\title{
Risk of spinal cord injury in patients with cervical spondylotic myelopathy and ossification of posterior longitudinal ligament: a national cohort study
}

\author{
Li-Fu Chen, MD,, ${ }^{1,2}$ Tsung-Hsi Tu, MD,, 2,3 Yu-Chun Chen, MD, PhD,, 2,45 Jau-Ching Wu, MD, PhD, 2,3 \\ Peng-Yuan Chang, MD, 2,3 Laura Liu, MD, PhD, ${ }^{6,7}$ Wen-Cheng Huang, MD, PhD, ${ }^{2,3}$ Su-Shun Lo, MD, ${ }^{2}$ \\ and Henrich Cheng, MD, PhD $2,3,8$
}

\begin{abstract}
${ }^{1}$ Department of Emergency Medicine, National Yang-Ming University Hospital, I-Lan; ${ }^{2}$ Faculty of Medicine, National Yang-Ming University, Taipei; ${ }^{3}$ Department of Neurosurgery, Neurological Institute, Taipei Veterans General Hospital, Taipei; ${ }^{4}$ Department of Medical Research and Education, National Yang-Ming University Hospital, I-Lan; ${ }^{5}$ Institute of Hospital and Health Care Administration, National Yang-Ming University School of Medicine, Taipei; ${ }^{6}$ Department of Ophthalmology, Chang Gung Memorial Hospital, Taoyuan; ${ }^{7}$ College of Medicine, Chang Gung University, Taoyuan; and ${ }^{8}$ Institute of Pharmacology, National Yang-Ming University, Taipei, Taiwan
\end{abstract}

OBJECTIVE This study aimed to estimate the risk of spinal cord injury (SCI) in patients with cervical spondylotic myelopathy (CSM) with and without ossification of posterior longitudinal ligament (OPLL). Also, the study compared the incidence rates of $\mathrm{SCl}$ in patients who were managed surgically and conservatively.

METHODS This retrospective cohort study covering 15 years analyzed the incidence of SCI in patients with CSM. All patients, identified from the National Health Insurance Research Database, were hospitalized with the diagnosis of CSM and followed up during the study period. These patients with CSM were categorized into 4 groups according to whether they had OPLL or not and whether they received surgery or not: 1) surgically managed CSM without OPLL; 2) conservatively managed CSM without OPLL; 3) surgically managed CSM with OPLL; and 4) conservatively managed CSM with OPLL. The incidence rates of subsequent SCl in each group during follow-up were then compared. Kaplan-Meier and Cox regression analyses were performed to compare the risk of $\mathrm{SCl}$ between the groups.

RESULTS Between January 1, 1999, and December 31, 2013, there were 17,258 patients with CSM who were followed up for 89,003.78 person-years. The overall incidence of SCI in these patients with CSM was 2.022 per 1000 personyears. Patients who had CSM with OPLL and were conservatively managed had the highest incidence of SCl, at 4.11 per 1000 person-years. Patients who had CSM with OPLL and were surgically managed had a lower incidence of SCI, at 3.69 per 1000 person-years. Patients who had CSM without OPLL and were conservatively managed had an even lower incidence of $\mathrm{SCl}$, at 2.41 per 1000 person-years. Patients who had CSM without OPLL and were surgically managed had the lowest incidence of SCI, at 1.31 per 1000 person-years. The Cox regression model demonstrated that SCls are significantly more likely to happen in male patients and in those with OPLL (HR 2.00 and 2.24, $p<0.001$ and $p=0.007$, respectively). Surgery could significantly lower the risk for approximately $50 \%$ of patients (HR $0.52, p<0.001)$.

CONCLUSIONS Patients with CSM had an overall incidence rate of $\mathrm{SCl}$ at approximately $0.2 \%$ per year. Male sex, the coexistence of OPLL, and conservative management are twice as likely to be associated with subsequent SCl. Surgery is therefore suggested for male patients with CSM who also have OPLL.

http://thejns.org/doi/abs/10.3171/2016.3.FOCUS1663

KEY WORDS cervical spondylotic myelopathy; ossification of posterior longitudinal ligament; spinal cord injury

ABBREVIATIONS CSM = cervical spondylotic myelopathy; mJOA = modified Japanese Orthopaedic Association; NHIRD = National Health Insurance Research Database; $\mathrm{NHRI}=$ National Health Research Institutes; OPLL = ossification of posterior longitudinal ligament; $\mathrm{SCl}$ = spinal cord injury. 
$\mathrm{C}$ ERVICAL spondylotic myelopathy (CSM) causes spinal cord dysfunction of various degrees and can be associated with multiple pathologies such as degenerative disc disease, hypertrophy of ligamentum flavum, or ossification of posterior longitudinal ligament (OPLL). The risk factors, optimal management, and prognosis of CSM remain uncertain and are an issue of debate in neurosurgery. ${ }^{20}$ Due to the predisposing factor of cervical spinal stenosis, it seems reasonable to consider patients with CSM as a high-risk group for subsequent spinal cord injury (SCI). Therefore, some surgeons would suggest early surgery for patients with CSM to ameliorate the risk of SCI. ${ }^{2,9,19,21,22,24,27,33}$ However, there are insufficient data to correlate CSM with SCI, and whether the risk of SCI can be altered by surgical intervention remains elusive.

Management of OPLL-related CSM remains challenging in neurosurgery, because surgery for OPLL is often difficult and may be accompanied by some serious complications. Strategies to manage CSM in patients with OPLL are thus varied, and the timing of intervention is quite debatable, especially when the symptoms are mild. Theoretically, CSM with OPLL is more problematic than the CSM without OPLL, because OPLL may cause more mass effect, more static compression, and more neurological symptoms. However, it is still not clear whether the incidence of SCI would be higher if the patients who have CSM with OPLL are managed conservatively without surgery. This issue is difficult to address because both OPLL and SCI are rare. To investigate the risk of SCI in patients with CSM and OPLL, a large cohort study with a longitudinal follow-up period longer than a decade is necessary.

There are more reports of OPLL in East Asian countries, for example Japan and Taiwan, than in those with predominantly Caucasian ethnicities. ${ }^{33}$ Therefore, the above-mentioned question regarding SCI in patients with CSM and OPLL would be best answered by a cohort study using Taiwan's National Health Insurance Research Database (NHIRD). The current study aimed to analyze the incidence of subsequent SCI in patients with CSM. The differences in risk of SCI were compared between patients with CSM not only with and without OPLL, but also with and without surgery. The NHIRD, a national database containing more than 23 million administered insured Taiwanese residents accumulated between January 1, 1999, and December 31, 2013, covers more than $99 \%$ of the population. This unique government-operated insurance system finances health care for the entire population by offering unrestricted access to any health care provider of the patient's choice. The universal and comprehensive coverage of the NHIRD provided us with a unique chance for such an analysis of SCI in patients with CSM.

\section{Methods}

\section{The NHIRD}

This study used the NHIRD, provided by the National Health Research Institutes (NHRI) of Taiwan. The database includes all claims data (mainly for financial purpos- es) from Taiwan's National Health Insurance program, a government-operated health care socio-welfare program covering basically the entire population of Taiwan. This study was approved by the institutional review board of Taipei Veterans General Hospital, Taiwan. Furthermore, it was impossible to trace back to each individual's data because the NHIRD is composed of deidentified secondary data released for research purposes.

\section{Identification of CSM and OPLL}

The patients with CSM in the current study were defined as adult patients (age 40-80 years) who had been hospitalized for CSM during the study period. In the NHIRD, the diagnosis of every admission is recorded by the International Classification of Diseases, 9th Revision (ICD-9). All hospitalized patients discharged with the diagnostic code for CSM (721.1) were identified from the cohort during 1999 to 2013. Also, those with OPLL of the cervical region (723.7) were identified using a similar method for subsequent analysis. The date of the incidence of CSM (index date) was designated as the first date of each patient's specific hospitalization. The incidence of hospitalization for CSM was identified as including patients who were followed up for more than 2 years and newly hospitalized with the above-mentioned discharge code for CSM between January 1, 1999, and December 31,2013 . The incidence rates in the study were estimated by the incidence density. Patients were thus divided into 2 groups: CSM with OPLL and CSM without OPLL.

\section{Surgical Versus Conservative Management}

All the patients with CSM, including those with and without OPLL, were then divided by whether they received surgical treatment or not. Surgery for CSM was determined based on any occurrence of hospitalization with procedure codes for spinal decompression $(03.02,03.4 \mathrm{X}$, $80.99,80.51$ ) or spinal fusion (ICD-9 procedure codes 81.02-3, 84.61-2) within the next 12 months following the indexed date. These procedure codes included basically all surgical management of CSM, including both anterior and posterior approaches (e.g., cervical discectomy, corpectomy, laminectomy, laminoplasty, and anterior or posterior spinal fusion operations with or without instrumentation). Theoretically, most of the surgical approaches for CSM caused by OPLL were also included (e.g., anterior, posterior, and combined anterior and posterior approaches). The surgical group was composed of patients who underwent any one of the above-mentioned surgery methods after the index date. The conservatively managed group was composed of patients who had no record of the above-mentioned surgical procedures (i.e., did not receive any of the operations).

Subsequently, all of the identified patients with CSM were divided into 4 groups according to whether they had OPLL, and whether they were treated with surgery (Fig. 1). The groups were classified as follows: patients with 1) surgically managed CSM without OPLL; 2) conservatively managed CSM without OPLL; 3) surgically managed CSM with OPLL; or 4) conservatively managed CSM with OPLL. 


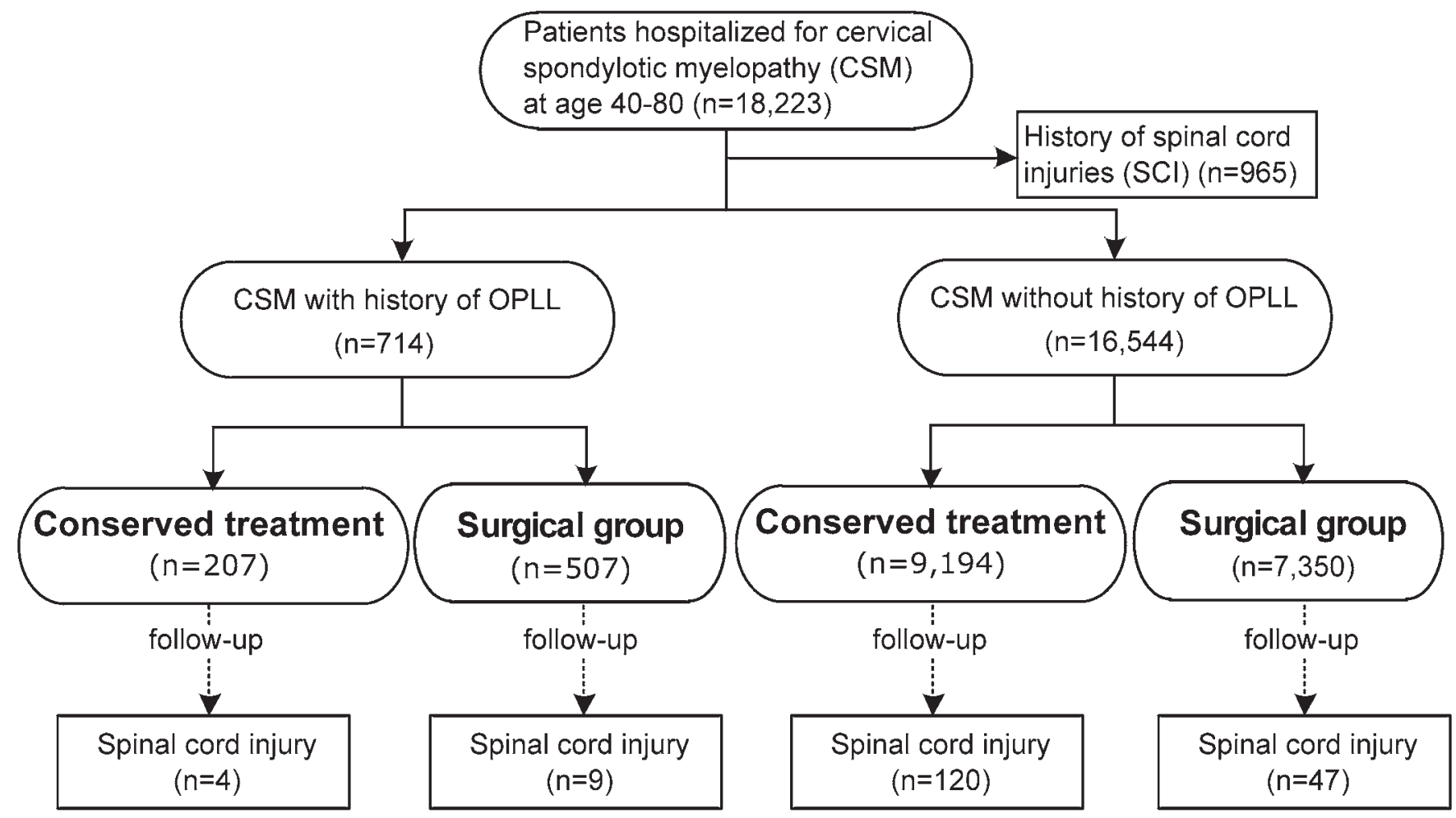

FIG. 1. Chart showing the flow of data processing of this cohort study.

\section{Identification of $\mathrm{SCl}$}

Cervical SCI was considered the end point of the study, the most clinically relevant final outcome of CSM. Hospitalization for cervical SCI was defined based on the date of hospitalization for SCI of the cervical region, which had medical records of a discharge diagnostic code for cervical SCI (ICD-9 codes 952.0X, 806.0-1) after the indexed date.

Prior admission for cervical SCI was determined based on hospitalization records with corresponding discharge diagnostic codes (ICD-9 codes 952.0X, 806.0-1) before the index date. After exclusion of all prior cervical SCI, all patients with CSM were followed up for subsequent occurrences of SCI, death, or for up to 10 years, until the end of 2013.

\section{Ascertainment of Covariates}

Adjustment was made by calculation of comorbidities, including hypertension (401-5.X), diabetes mellitus (250.X), osteoporosis (733.0X), and osteoarthrosis (ICD-9 code 715.X), which were all designated as covariates in the current study. Ascertainment of these covariates was also determined by the presence of either ICD-9 diagnostic codes in outpatient records or discharge codes in hospitalization records 6 months before the index date to the date of outcome event or the end of follow-up. To further adjust baseline differences between the groups, logistic regression analysis included all covariates.

Cervical SCI was considered to be the outcome of CSM, the end point of the current study. Thus, the incidence rates of subsequent SCI in the 4 groups were compared.

\section{Statistical Analysis}

All of the data were calculated using the Stata software (StataCorp) for descriptive statistics and contingency tables. The incidence density method was used to estimate the incidence rates for CSM. The Kaplan-Meier method and log-rank test were used to estimate and compare the incidence rates of hospitalizations for SCI. The Cox proportional hazard model with propensity scores was used to compare the incidence rates of subsequent SCI between the groups after adjustment for the aforementioned covariates. A probability value of 0.05 was considered statistically significant.

\section{Results}

\section{Incidence Rates of SCI in Patients Who Had CSM With and Without OPLL}

A total of 17,258 patients were hospitalized for CSM and followed for up to 10 years during the period from 1999 to 2013. For the total follow-up of $89,003.78$ personyears, there were 714 patients with CSM with OPLL, and 16,544 patients with CSM without OPLL. There were more male than female patients with CSM, regardless of whether or not they received surgical treatment (Fig. 1, Table 1).

A total of 180 patients had subsequent SCI. The overall incidence rate of SCI in patients with CSM, including those with and without OPLL, was 2.022 (95\% CI 1.7482.341) per 1000 person-years (Table 2). The incidence of SCI was significantly different in patients with and without OPLL, managed surgically and conservatively, respec- 
TABLE 1. Demographic characteristics and comorbidities of study population grouped by history of OPLL and operation* $^{*}$

\begin{tabular}{|c|c|c|c|c|c|}
\hline \multirow[b]{2}{*}{ Variable } & \multicolumn{2}{|c|}{ No. w/ CSM w/ OPLL (\%) } & \multicolumn{2}{|c|}{ No. w/ CSM w/o OPLL (\%) } & \multirow[b]{2}{*}{$\begin{array}{c}p \\
\text { Value }\end{array}$} \\
\hline & $\begin{array}{c}\text { Conservative } \\
\text { Treatment, } n=207\end{array}$ & $\begin{array}{l}\text { Surgical Group, } \\
n=507\end{array}$ & $\begin{array}{c}\text { Conservative } \\
\text { Treatment, } n=9194\end{array}$ & $\begin{array}{l}\text { Surgical Group, } \\
n=7350\end{array}$ & \\
\hline \multicolumn{6}{|l|}{ Demographic characteristics } \\
\hline Sex & & & & & $<0.001$ \\
\hline Female & $53(25.6)$ & $132(26.0)$ & $3676(40.0)$ & $2588(35.2)$ & \\
\hline Male & $154(74.4)$ & $375(74.0)$ & $5518(60.0)$ & $4762(64.8)$ & \\
\hline Mean age in yrs, \pm SD & $60.0 \pm 10.4$ & $62.2 \pm 11.1$ & $58.6 \pm 9.7$ & $62.1 \pm 10.5$ & $<0.001$ \\
\hline \multicolumn{6}{|l|}{ Comorbidities } \\
\hline Hypertension & & & & & $<0.001$ \\
\hline Yes & $69(33.3)$ & $107(21.1)$ & $2809(30.6)$ & $1767(24.0)$ & \\
\hline No & $138(66.7)$ & $400(78.9)$ & $6385(69.4)$ & $5583(76.0)$ & \\
\hline Diabetes & & & & & $<0.001$ \\
\hline Yes & $47(22.7)$ & $65(12.8)$ & $1497(16.3)$ & $1021(13.9)$ & \\
\hline No & $160(77.3)$ & $442(87.2)$ & $7697(83.7)$ & $6329(86.1)$ & \\
\hline Osteoporosis & & & & & $<0.001$ \\
\hline Yes & $2(1.0)$ & $6(1.2)$ & $229(2.5)$ & $85(1.2)$ & \\
\hline No & $205(99.0)$ & $501(98.8)$ & 8965 (97.5) & $7265(98.8)$ & \\
\hline Osteoarthrosis & & & & & $<0.001$ \\
\hline Yes & $19(9.2)$ & $21(4.1)$ & $714(7.8)$ & $445(6.1)$ & \\
\hline No & $188(90.8)$ & $486(95.9)$ & 8480 (92.2) & 6905 (93.9) & \\
\hline \multicolumn{6}{|l|}{ Outcome } \\
\hline SCls & $4(1.9)$ & $9(1.8)$ & $120(1.3)$ & $47(0.6)$ & $<0.001$ \\
\hline
\end{tabular}

* Population consisted of 17,258 patients who presented between January 1, 1999, and December 31, 2013.

tively. The incidence rates of SCI during the follow-up were significantly different in each of the 4 groups. The conservatively managed CSM with OPLL group had the highest incidence rate at 4.11 per 1000 person-years. The surgically managed CSM with OPLL group had the second highest rate of SCI, at 3.69 per 1000 person-years. Then the conservatively managed CSM without OPLL had a lower incidence rate of SCI, at 2.41 per 1000 personyears. Last, the surgically managed CSM without OPLL had the lowest rate of SCI, at 1.31 per 1000 person-years.

Patients who had CSM with OPLL and who received conservative management were at higher risk of SCI than those who had CSM with OPLL and who were managed by surgery (HR 2.89 and 2.68, respectively). They were also at higher risk than those with CSM without OPLL who received conservative management (HR 2.06, $\mathrm{p}<$ 0.05 for all 3 groups), and those with CSM without OPLL who were managed by surgery (reference group). The OPLL significantly worsened the prognosis of CSM and the surgical management significantly reduced the risk of subsequent SCI.

\section{Adjusted Hazard Ratios for SCl in Patients Who Had CSM With and Without OPLL}

Of the total of 17,258 patients who were hospitalized for CSM and followed up in this 15-year cohort, there were 180 patients who subsequently suffered from SCI. By analysis of the covariates, sex, age, and OPLL were identified as significant risk factors for SCI in these patients with CSM (Table 3).

Male patients with CSM and those with OPLL had a higher risk of subsequent SCI (HR 2.00 and 2.24, p < 0.001 and $p=0.007$, respectively). Those patients with CSM who received surgery were less likely to have subsequent SCI (HR 0.52, p < 0.001). Other covariates analyzed, including age, hypertension, diabetes, osteoporosis, and osteoarthrosis, had no effect on the risk of SCI.

A Kaplan-Meier analysis of this cohort of patients with CSM demonstrated that patients who had CSM with OPLL and who were managed conservatively had the highest incidence of SCI compared with those who had CSM with OPLL and who were managed with surgery. Patients who had CSM with OPLL and who were managed conservatively were also at higher risk than those who had CSM without OPLL and who were managed conservatively, and those who had CSM without OPLL and who were managed with surgery ( $<<0.001$, log-rank test) (Fig. 2).

The Cox proportional hazard model with adjustment for the aforementioned covariates demonstrated that female patients with CSM who had surgery but no OPLL were least likely to suffer from subsequent SCI (Fig. 3).

\section{Discussion}

To date, this was the largest cohort of patients with CSM (consisting of 17,258 subjects) with the longest follow-up 
TABLE 2. Incidence rates and adjusted hazard ratios for SCI grouped by history of OPLL and operation

\begin{tabular}{|c|c|c|c|c|c|}
\hline \multirow[b]{2}{*}{ Factor } & \multirow[b]{2}{*}{ Total Sample* } & \multicolumn{2}{|c|}{ CSM w/ OPLL* $^{*}$} & \multicolumn{2}{|c|}{ CSM w/o OPLL* } \\
\hline & & $\begin{array}{l}\text { Conservatively } \\
\text { Managed Group }\end{array}$ & Surgical Group & $\begin{array}{l}\text { Conservatively } \\
\text { Managed Group }\end{array}$ & Surgical Group \\
\hline $\begin{array}{l}\text { Incidence of hospitaliza- } \\
\text { tion for SCl }(95 \% \mathrm{Cl})\end{array}$ & $2.02(1.75-2.34)$ & $4.11(1.54-10.96)$ & $3.69(1.92-7.08)$ & $2.41(2.02-2.89)$ & $1.31(0.98-1.74)$ \\
\hline $\begin{array}{l}\text { No. of patients hospital- } \\
\text { ized for } \mathrm{SCl}\end{array}$ & 180 & 4 & 9 & 120 & 47 \\
\hline Observed person-years & $89,003.8$ & 972.6 & 2441.4 & $49,720.4$ & $35,869.3$ \\
\hline Adjusted HR $(95 \% \mathrm{Cl}) \dagger$ & & $2.89(1.04-8.03) \ddagger$ & $2.68(1.31-5.46) \S$ & $2.06(1.47-2.90) \uparrow$ & Reference \\
\hline \multicolumn{6}{|c|}{$\begin{array}{l}\text { * Rates per } 1000 \text { person-years. } \\
\dagger \text { Hazard ratios adjusted for age, sex, and comorbidities including diabetes, hypertension, osteoporosis, and osteoarthrosis. } \\
\text { † } p<0.05 \text {. } \\
\S p<0.01 \\
\text { ๆ } p<0.001 .\end{array}$} \\
\hline
\end{tabular}

(15 years; 1999-2013) for subsequent SCI. These patients were divided into 4 groups according to whether they received surgery and whether there was OPLL. A total of 180 patients had SCI, which is perhaps the most drastic outcome of CSM, during the study period (at an incidence rate of 2.02 per 1000 person-years). Patients with OPLL were at least twice as likely to have subsequent SCI (HR $2.24, p=0.007)$. The cohort also demonstrated that surgical treatment could significantly lower the risk of SCI by approximately $50 \%$ (HR $0.52, \mathrm{p}<0.001$ ). The study also demonstrated that male sex was a risk factor for SCI (HR $2.00, \mathrm{p}<0.001$ ), which corroborated most other studies of SCI. ${ }^{6,30-33}$ The present study has the merit of using the national cohort in an area of higher prevalence of both SCI and OPLL to demonstrate risk factors of SCI in patients with CSM. The study provides a reference guide for future management of CSM.

The natural history of CSM is mixed and variable, with pathobiological mechanisms mainly unknown. In a systematic review on the natural course of CSM, Karadimas et al. reported that $20 \%-62 \%$ of patients will deteriorate neurologically at 3-6 years without surgical intervention. ${ }^{15}$ Their review underscores the uncertainty of widely varied clinical presentation of CSM and the clinical dilemma that roughly half of patients may live with CSM without surgical treatment. The choice of optimal treatments and the timing of any intervention remain controversial and reflect a lack of reliable clinical and radiographical factors to predict patients who will experience deterioration. The different assessment tools also contribute to this large fluctuation of natural course. In a systematic review on the validity, reliability, and responsiveness of assessment tools for patients with CSM, Singh et al. proposed the combined use of functional measures such as the Myelopathy Disability Index, modified Japanese Orthopaedic Association (mJOA), and Nurick grade, with more sensitive and qualitative assessment including a variety of walking tests or the grip and release test to better define the optimal treatment and the prognostic value of certain characteristics. ${ }^{29}$

The clinical results of conservative and surgical management of CSM reported in the literature are conflicting.
In a small randomized trial performed in 68 patients with a milder degree of CSM in whom nonoperative surgical treatment was compared with surgery during a 10-year follow-up period, Kadanka et al. reported no difference in mJOA scores between nonoperative $(\mathrm{n}=35)$ and surgical groups $(\mathrm{n}=33)$ at 10 years. ${ }^{13,14}$ Another prospective cohort study $(\mathrm{n}=62)$ by Sampath et al. reported the outcomes of nonoperative and surgical treatment of CSM and concluded that surgically treated patients had a significant improvement in functional status and overall pain. ${ }^{28} \mathrm{How}-$ ever, the authors did not directly compare the 2 groups. Yoshimatsu et al. retrospectively compared 32 surgically treated and 69 nonoperatively managed patients with CSM and found improvement in the mJOA score in $78 \%$ of surgically treated patients and $23 \%$ of nonoperatively managed patients. ${ }^{34}$ In the nonoperative care group, they also found that rigorous nonoperative care had better improvement outcomes (38\%) than nonrigorous nonoperative care $(6 \%)$. These results led to a clinical recommendation of not routinely prescribing nonoperative treatment as the primary modality in patients with moderate to severe CSM, and suggesting careful observation of neurological

TABLE 3. Adjusted hazard ratios for SCI

\begin{tabular}{lccc}
\hline \multicolumn{1}{c}{ Variable } & Adjusted HR & $95 \% \mathrm{Cl}$ & $\mathrm{p} \mathrm{Value}$ \\
\hline $\begin{array}{l}\text { Demographic characteristics } \\
\text { Sex }\end{array}$ & & & \\
\hline$\quad$ Male vs female & 2.00 & $1.42-2.82$ & $<0.001^{*}$ \\
\hline$\quad$ Age & 0.99 & $0.98-1.01$ & 0.091 \\
\hline Patients w/ history of OPLL & 2.24 & $1.25-4.00$ & $0.007 \dagger$ \\
\hline Surgical intervention & 0.52 & $0.38-0.72$ & $<0.001^{*}$ \\
\hline Comorbidities & & & \\
\hline$\quad$ Hypertension & 0.68 & $0.46-1.01$ & 0.054 \\
\hline$\quad$ Diabetes & 1.00 & $0.63-1.60$ & 0.992 \\
\hline$\quad$ Osteoporosis & 0.98 & $0.31-3.13$ & 0.977 \\
\hline$\quad$ Osteoarthrosis & 1.66 & $0.99-2.79$ & 0.056 \\
\hline * Significant at $p<0.001$. & & & \\
$\dagger$ Significant at $p<0.01$. & & &
\end{tabular}




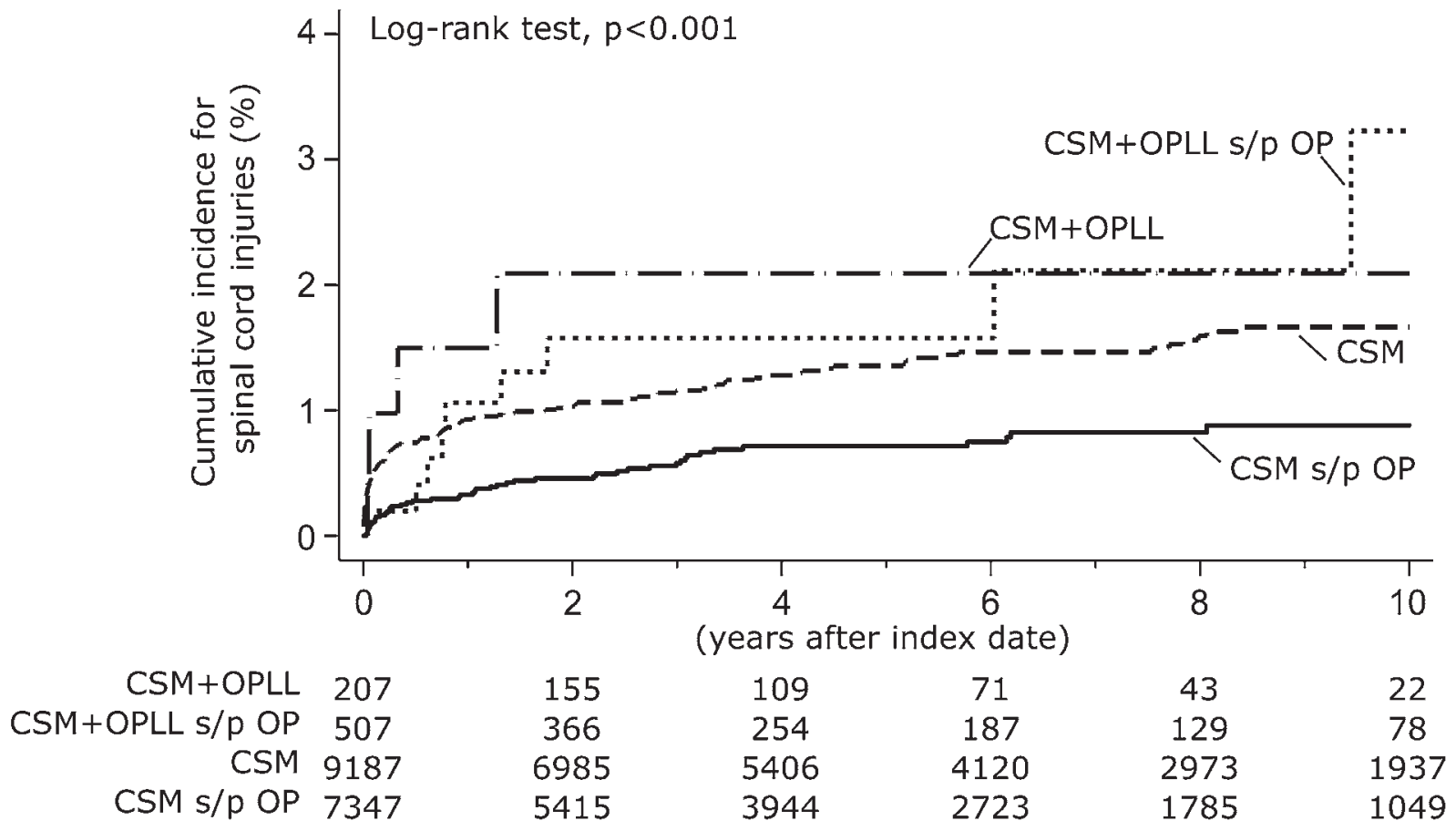

FIG. 2. Kaplan-Meier analysis of cumulative incidence rates of cervical SCI in this national cohort of patients with $\mathrm{CSM}(\mathrm{n}=$ 17,258). s/p OP = status postoperation.

deterioration if nonoperative treatment is selected in patients with mild CSM. ${ }^{25}$

Cervical spondylotic myelopathy has been recognized as a major disease that constitutes a significant cause of disability in adult populations. ${ }^{4,5,8}$ However, the optimal treatment strategy for CSM remains a clinical challenge in which multiple areas of controversy exist. Although the supporters of conservative treatment may assert the fact

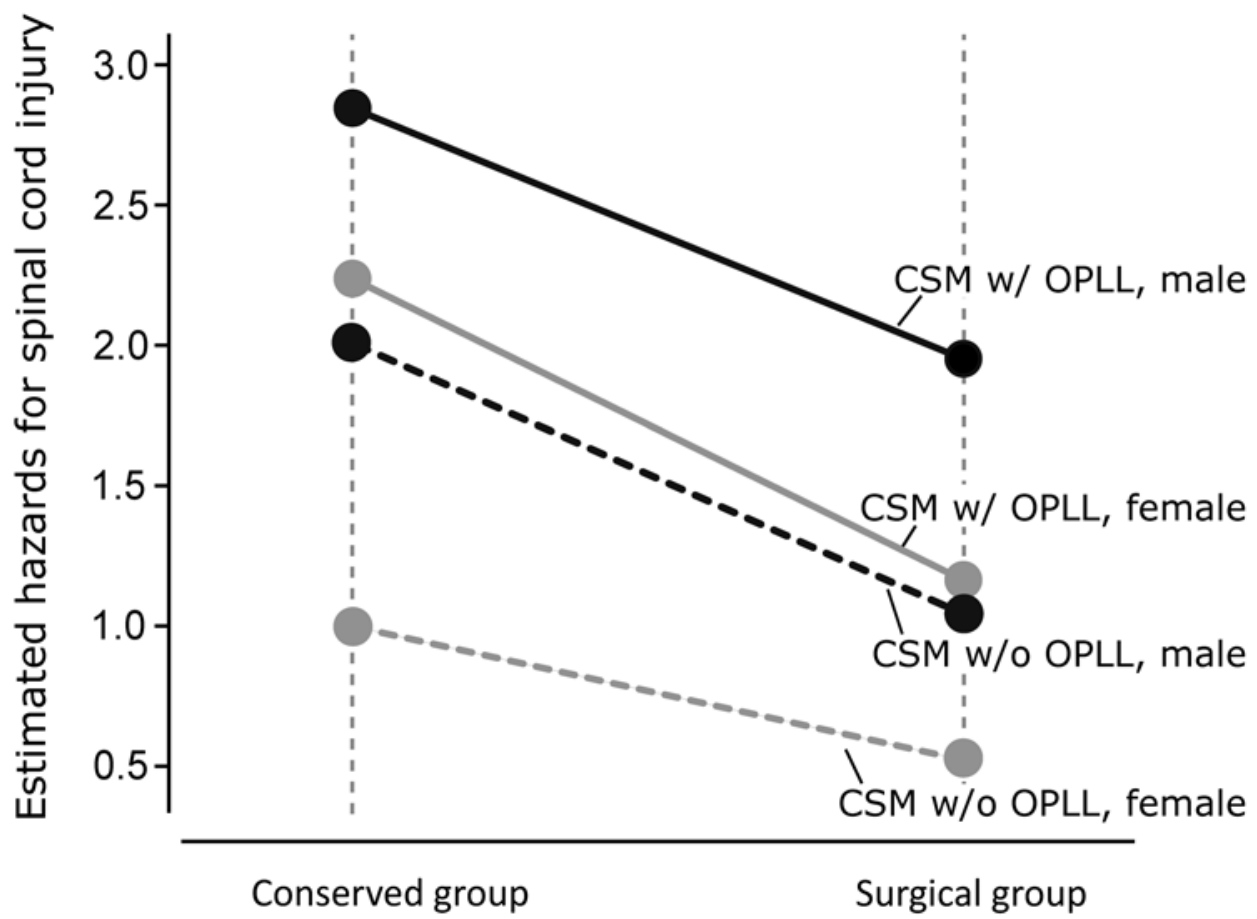

FIG. 3. Cox regression model demonstrating the risk factors for cervical SCl in patients with CSM, including sex, presence of OPLL, and surgery $(n=17,258)$. 
that the failure rate for surgical treatment may account for $15 \%-30 \%$ of the cases, ${ }^{26}$ surgical decompression and stabilization of the spine is nonetheless advocated for patients with progressive or severe symptoms of CSM., ${ }^{1,7,26}$ In a previous large data study conducted by Wu et al., cervical SCI was found to be more likely to happen in patients with OPLL, with an estimated 32.16-fold higher risk than in the age- and sex-matched group. ${ }^{31}$ That being said, conservative treatment for patients with established OPLL should be conducted with great caution. The result of the aforementioned study was supported by other previous publications that specifically tried to identify the risk factors contributing to SCI in patients with OPLL. To date, some of the identified risk factors included older age, mixed or segmental types of OPLL, preoperative neurological status, severe cord compression ratio, increased signal intensity on MR images, and so on..$^{10,16-18,23}$ Although there remains a great controversy about the proper surgical strategy for treating patients with OPLL (e.g., anterior vs posterior), ${ }^{11,12,16}$ it is generally agreed that surgical intervention should be provided for patients with severe presentations of OPLL as indicated radiographically or clinically, and that the strategy should be tailored to the individual. . $^{3,5,10,16-18,26,31}$

There are limitations to the present study. There was inherent heterogeneity of these patients with CSM, including their neurological function, techniques used for and extent of surgery, and degree of SCI. It was impossible to look into the detailed medical records of each patient in this cohort, because the individual information was not available in the NHIRD. The data in the NHIRD were initially collected for billing purposes. Therefore, the actual neurological function, number of spinal segments treated, the findings during the operation, and reports of image evaluations were all unavailable. The protective effect of surgery was derived from outcomes of a mixture of various kinds of surgical approaches, including anterior and posterior, successful and failed, and instrumented fusion and decompression only. Furthermore, the study only included patients with CSM who were hospitalized. It may be supposed that there were many more patients with less severe symptoms who required no hospitalization but who should also be included for follow-up for subsequent SCI. Therefore, the risk of SCI in patients with CSM could have been underestimated. However, the results of the current study successfully demonstrated the significance of an increased risk of SCI in patients with CSM. Although the data might advocate surgery when considering management of CSM and prevention of SCI, the study did not take into account the risks and complications associated with surgery itself in these patients with CSM. Future investigations on a larger scale and with a longer follow-up period, and perhaps a true control group of "normal" patients (i.e., patients without either CSM or OPLL) are required to calculate the true hazard ratio.

The strength of the current study was the accuracy of identification of CSM-related hospitalization, surgical treatment, and subsequent SCI. Because the NHIRD data underwent rigorous internal review for the claims of the admission, cost of surgery, and socio-welfare benefit program for SCI, these inclusion criteria, intervention (surgery), and study end point (i.e., SCI) should be sound and reproducible. Moreover, the longitudinal follow-up of 10 years is invaluable for the observation of SCI. The uniquely comprehensive coverage of health care services of the entire population yielded nearly a $100 \%$ follow-up rate. Therefore, the estimated incidence rates of SCI were extremely accurate. Very few other studies could reach a follow-up rate this high, the inclusion of so many patients, and span a long enough period to catch the occurrence of SCI.

\section{Conclusions}

Patients with CSM had an overall incidence rate of SCI of approximately $0.2 \%$ per year. Male sex, the coexistence of OPLL, and conservative management are twice as likely to be associated with subsequent SCI. Surgery is therefore suggested for male patients with CSM who also have OPLL.

\section{Acknowledgments}

This study was based partly on data from the NHRI database provided by the Bureau of National Health Insurance, Department of Health, and managed by NHRI in Taiwan. The interpretation and conclusions contained herein do not represent those of the Bureau of National Health Insurance, the Department of Health, or NHRI.

\section{References}

1. al-Mefty O, Harkey HL, Marawi I, Haines DE, Peeler DF, Wilner HI, et al: Experimental chronic compressive cervical myelopathy. J Neurosurg 79:550-561, 1993

2. Anderson PA, Matz PG, Groff MW, Heary RF, Holly LT, Kaiser MG, et al: Laminectomy and fusion for the treatment of cervical degenerative myelopathy. J Neurosurg Spine 11:150-156, 2009

3. Baron EM, Young WF: Cervical spondylotic myelopathy: a brief review of its pathophysiology, clinical course, and diagnosis. Neurosurgery 60 (1 Supp1 1):S35-S41, 2007

4. Chang V, Holly LT: Controversies in the management of cervical spondylotic myelopathy. J Neurosurg Sci 57:241-252, 2013

5. Chen Y, Yang L, Liu Y, Yang H, Wang X, Chen D: Surgical results and prognostic factors of anterior cervical corpectomy and fusion for ossification of the posterior longitudinal ligament. PLoS One 9:e102008, 2014

6. Chien LC, Wu JC, Chen YC, Liu L, Huang WC, Chen TJ, et al: Age, sex, and socio-economic status affect the incidence of pediatric spinal cord injury: an eleven-year national cohort study. PLoS One 7:e39264, 2012

7. Edwards CC II, Riew KD, Anderson PA, Hilibrand AS, Vaccaro AF: Cervical myelopathy: current diagnostic and treatment strategies. Spine J 3:68-81, 2003

8. Ghogawala Z, Benzel EC, Heary RF, Riew KD, Albert TJ, Butler WE, et al: Cervical spondylotic myelopathy surgical trial: randomized, controlled trial design and rationale. Neurosurgery 75:334-346, 2014

9. Holly LT, Matz PG, Anderson PA, Groff MW, Heary RF, Kaiser MG, et al: Clinical prognostic indicators of surgical outcome in cervical spondylotic myelopathy. J Neurosurg Spine 11:112-118, 2009

10. Inamasu J, Guiot BH: Factors predictive of surgical outcome for ossification of the posterior longitudinal ligament of the cervical spine. J Neurosurg Sci 53:93-100, 2009

11. Iwasaki M, Okuda S, Miyauchi A, Sakaura H, Mukai Y, Yonenobu K, et al: Surgical strategy for cervical myelopathy 
due to ossification of the posterior longitudinal ligament: Part 1: Clinical results and limitations of laminoplasty. Spine (Phila Pa 1976) 32:647-653, 2007

12. Iwasaki M, Okuda S, Miyauchi A, Sakaura H, Mukai Y, Yonenobu K, et al: Surgical strategy for cervical myelopathy due to ossification of the posterior longitudinal ligament: Part 2: Advantages of anterior decompression and fusion over laminoplasty. Spine (Phila Pa 1976) 32:654-660, 2007

13. Kadaňka Z, Bednařík J, Novotný O, Urbánek I, Dušek L: Cervical spondylotic myelopathy: conservative versus surgical treatment after 10 years. Eur Spine J 20:1533-1538, 2011

14. Kadanka Z, Mares M, Bednanik J, Smrcka V, Krbec M, Stejskal L, et al: Approaches to spondylotic cervical myelopathy: conservative versus surgical results in a 3 -year follow-up study. Spine (Phila Pa 1976) 27:2205-2201, 2002

15. Karadimas SK, Erwin WM, Ely CG, Dettori JR, Fehlings MG: Pathophysiology and natural history of cervical spondylotic myelopathy. Spine (Phila Pa 1976) 38 (22 Suppl 1):S21-S36, 2013

16. Kim B, Yoon H, Shin HC, Kim KN, Yi S, Shin DA, et al: Surgical outcome and prognostic factors of anterior decompression and fusion for cervical compressive myelopathy due to ossification of the posterior longitudinal ligament. Spine $\mathbf{J}$ 15:875-884, 2015

17. Kwon SY, Shin JJ, Lee JH, Cho WH: Prognostic factors for surgical outcome in spinal cord injury associated with ossification of the posterior longitudinal ligament (OPLL). J Orthop Surg 10:94, 2015

18. Li H, Jiang LS, Dai LY: A review of prognostic factors for surgical outcome of ossification of the posterior longitudinal ligament of cervical spine. Eur Spine J 17:1277-1288, 2008

19. Matz PG, Anderson PA, Groff MW, Heary RF, Holly LT, Kaiser MG, et al: Cervical laminoplasty for the treatment of cervical degenerative myelopathy. J Neurosurg Spine 11:157-169, 2009

20. Matz PG, Anderson PA, Holly LT, Groff MW, Heary RF, Kaiser MG, et al: The natural history of cervical spondylotic myelopathy. J Neurosurg Spine 11:104-111, 2009

21. Matz PG, Holly LT, Mummaneni PV, Anderson PA, Groff MW, Heary RF, et al: Anterior cervical surgery for the treatment of cervical degenerative myelopathy. J Neurosurg Spine 11:170-173, 2009

22. Mummaneni PV, Kaiser MG, Matz PG, Anderson PA, Groff MW, Heary RF, et al: Cervical surgical techniques for the treatment of cervical spondylotic myelopathy. J Neurosurg Spine 11:130-141, 2009

23. Onishi E, Sakamoto A, Murata S, Matsushita M: Risk factors for acute cervical spinal cord injury associated with ossification of the posterior longitudinal ligament. Spine (Phila Pa 1976) 37:660-666, 2012

24. Resnick DK, Anderson PA, Kaiser MG, Groff MW, Heary RF, Holly LT, et al: Electrophysiological monitoring during surgery for cervical degenerative myelopathy and radiculopathy. J Neurosurg Spine 11:245-252, 2009

25. Rhee JM, Shamji MF, Erwin WM, Bransford RJ, Yoon ST, Smith JS, et al: Nonoperative management of cervical myelopathy: a systematic review. Spine (Phila Pa 1976) 38 (22 Suppl 1):S55-S67, 2013

26. Rowland LP: Surgical treatment of cervical spondylotic myelopathy: time for a controlled trial. Neurology 42:5-13, 1992
27. Ryken TC, Heary RF, Matz PG, Anderson PA, Groff MW, Holly LT, et al: Cervical laminectomy for the treatment of cervical degenerative myelopathy. J Neurosurg Spine 11:142-149, 2009

28. Sampath P, Bendebba M, Davis JD, Ducker TB: Outcome of patients treated for cervical myelopathy. A prospective, multicenter study with independent clinical review. Spine (Phila Pa 1976) 25:670-676, 2000

29. Singh A, Tetreault L, Casey A, Laing R, Statham P, Fehlings MG: A summary of assessment tools for patients suffering from cervical spondylotic myelopathy: a systematic review on validity, reliability and responsiveness. Eur Spine J 24 (Suppl 2):209-228, 2015

30. Wu JC, Chen YC, Liu L, Chen TJ, Huang WC, Cheng H, et al: Effects of age, gender, and socio-economic status on the incidence of spinal cord injury: an assessment using the eleven-year comprehensive nationwide database of Taiwan. J Neurotrauma 29:889-897, 2012

31. Wu JC, Chen YC, Liu L, Huang WC, Chen TJ, Lo SS, et al: Conservatively treated ossification of the posterior longitudinal ligament increases the risk of spinal cord injury: a nationwide cohort study. J Neurotrauma 29:462-468, 2012

32. Wu JC, Huang WC, Chen YC, Tu TH, Tsai YA, Huang SF, et al: Acidic fibroblast growth factor for repair of human spinal cord injury: a clinical trial. J Neurosurg Spine 15:216-227, 2011

33. Wu JC, Ko CC, Yen YS, Huang WC, Chen YC, Liu L, et al: Epidemiology of cervical spondylotic myelopathy and its risk of causing spinal cord injury: a national cohort study. Neurosurg Focus 35(1):E10, 2013

34. Yoshimatsu H, Nagata K, Goto H, Sonoda K, Ando N, Imoto $\mathrm{H}$, et al: Conservative treatment for cervical spondylotic myelopathy. Prediction of treatment effects by multivariate analysis. Spine J 1:269-273, 2001

\section{Disclosures}

The authors report no conflict of interest concerning the materials or methods used in this study or the findings specified in this paper.

\section{Author Contributions}

Conception and design: Wu, LF Chen, YC Chen, Liu. Acquisition of data: Wu, LF Chen, Tu, YC Chen, Chang. Analysis and interpretation of data: $\mathrm{Wu}, \mathrm{LF}$ Chen, Tu, YC Chen, Chang. Drafting the article: Wu, LF Chen, Tu, YC Chen, Chang, Liu, Lo. Critically revising the article: Wu, LF Chen, Tu, YC Chen, Chang, Liu. Reviewed submitted version of manuscript: Wu, YC Chen, Liu, Huang, Lo, Cheng. Approved the final version of the manuscript on behalf of all authors: Wu. Statistical analysis: $\mathrm{Wu}$, YC Chen, Huang, Lo, Cheng. Administrative/technical/material support: Wu, YC Chen, Huang, Lo, Cheng. Study supervision: $\mathrm{Wu}$, YC Chen, Huang, Cheng.

\section{Correspondence}

Jau-Ching Wu, Department of Neurosurgery, Neurological Institute, Taipei Veterans General Hospital, Rm. 525, 17F, No. 201, Shih-Pai Rd., Sec. 2, Beitou District, Taipei 11217, Taiwan. email: jauching@gmail.com. 